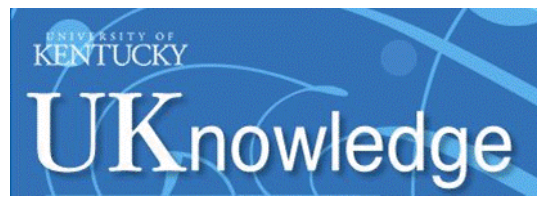

University of Kentucky

UKnowledge

\title{
Relationship and Injury Trends in the Homicide of Women Across the Lifespan: A Research Note
}

\author{
Carol E. Jordan \\ University of Kentucky, carol.j@uky.edu \\ Adam J. Pritchard \\ University of Kentucky, adam.pritchard@ucf.edu \\ Danielle Duckett \\ University of Kentucky \\ Pamela Wilcox \\ University of Cincinnati - Main Campus, pamela.wilcox@uc.edu \\ Tracey Corey \\ Kentucky Chief Medical Examiner's Office, tracey.corey@ky.gov
}

See next page for additional authors

Follow this and additional works at: https://uknowledge.uky.edu/ipsvaw_facpub

Part of the Criminal Law Commons, Criminal Procedure Commons, Law and Gender Commons, Psychology Commons, Social Work Commons, and the Sociology Commons

Right click to open a feedback form in a new tab to let us know how this document benefits you.

\section{Recommended Citation}

Jordan, C.E., Pritchard, A.J., Duckett, D., Wilcox, P., Corey, T., \& Combest, M. Relationship and injury trends in the homicide of women across the life span: A research note. Homicide Studies, 14(2), 181-192.

This Article is brought to you for free and open access by the Policy Studies on Violence Against Women at UKnowledge. It has been accepted for inclusion in Office for Policy Studies on Violence Against Women Publications by an authorized administrator of UKnowledge. For more information, please contact UKnowledge@lsv.uky.edu. 
Relationship and Injury Trends in the Homicide of Women Across the Lifespan: A Research Note

Digital Object Identifier (DOI)

http://dx.doi.org/10.1177/1088767910362328

Notes/Citation Information

Published in Homicide Studies, v. 14, no. 2, p. 181-192.

The manuscript provided, in accordance with publisher copyright rules, is the authors' postprint version.

Authors

Carol E. Jordan, Adam J. Pritchard, Danielle Duckett, Pamela Wilcox, Tracey Corey, and Mandy Combest 


\title{
Relationship and Injury Trends in the Homicide of Women Across the Life Span: A Research Note
}

\author{
Carol E. Jordan', Adam J. Pritchard', \\ Danielle Duckett', Pamela Wilcox', \\ Tracey Corey ${ }^{3}$, and Mandy Combest ${ }^{3}$
}

\begin{abstract}
In 2006, more than 3,600 women in the United States lost their lives to homicide. Descriptive data regarding homicides of women are beginning to reveal important complexities regarding victim-offender relationships, severity of injury, and age of female homicide victim. More specifically, there is some indication that the correlation between victim-offender relationship and injury severity may be conditional, depending on victim age. This retrospective review accessed medical examiner records of female homicide victims from 2002 through 2004, and its findings offer additional illumination on the trends in associations of injury and relationship variables in the homicide of women over their life span. The study also examined the utility of the recently proposed Homicide Injury Scale (HIS) created by Safarik and Jarvis as a potential tool to explore these complicated associations by quantifying injury severity and examining its interrelationships with victim-offender relationship and age in cases of female homicide in Kentucky.
\end{abstract}

\section{Keywords}

homicide, femicide, violence against women, injury

\footnotetext{
'University of Kentucky, Lexington

${ }^{2}$ University of Cincinnati, Cincinnati, Ohio

${ }^{3}$ Office of the Kentucky Chief Medical Examiner, Louisville

Corresponding Author:

Carol E. Jordan, Assistant Provost and Director, Center for Research on Violence Against Women, University of Kentucky, 108 Bowman Hall, Lexington, KY 40506-0059

Email: carolj@uky.edu
} 
Recent data indicate that in 2006, more than 3,600 women in the United States lost their lives to homicide (Snyder, Finnegan, \& Kang, 2007). The National Violent Death Reporting System (NVDRS) analysis of homicide in 16 reporting states reports a homicide rate of 2.6 per 1,000 females in the United States (Karch, Lubell, Friday, Patel, \& Williams, 2008). In seeking to understand homicides such as these, descriptive analyses have often highlighted such variables as the relationship of the victim to the offender, victim demographics, and manner of death (Nelson \& Huff-Corzine, 1998).

\section{Lethal and Nonlethal Assaults Against Women: Victim-Offender Relationship}

When one compares the homicide of women versus that of men, well-documented differences in offender to victim relationship across gender lines emerge. Studies find that women are far more likely to be killed by an intimate partner, whereas men are more likely to die at the hands of a stranger or unidentified assailant (Kellermann \& Mercy, 1992; Koss et al., 1994; McGuire \& Pastore, 1996; Mercy \& Saltzman, 1989). In fact, among murder victims for every age group, females are much more likely than males to have been murdered by an intimate partner (Cooper \& Eaves, 1996; Fox \& Zawitz, 2007). This is not a new trend; between 1976 and 2005, intimate partner homicide has accounted for $30 \%$ of female victims but only $5 \%$ of male victims (Fox \& Zawitz, 2007). Similarly, Bachman and Saltzman (1995) reported that nearly $30 \%$ of female homicide victims are killed by their husbands, former husbands, or boyfriends, whereas just above $3 \%$ of male homicide victims are known to have been killed by their wives, former wives, or girlfriends. In one specific state, Moracco, Runyan, and Butts (1998) found that more than half of the 586 women killed were murdered by current or former intimate partners. More recently, the NVDRS reported that of intimate partner homicide cases captured from the 16 reporting states, $65 \%$ of victims were female and $78.4 \%$ of offenders were male (Karch et al., 2008).

Studies of femicide find a tie between lethal and nonlethal forms of violence. Specifically, homicides by intimate partners are often preceded by a history of physical and other forms of violence and a recent separation or attempt to separate from the relationship by the victim (Arbuckle et al., 1996; Browne \& Williams, 1993; Campbell, 1992; Campbell et al., 2003; Ellis \& DeKeseredy, 1997; Moracco et al., 1998; Sev'er, 1997; Stark \& Flitcraft, 1996; Wilson \& Daly, 1993). Studies of homicidesuicide evidence similar patterns. In a study of 116 homicide-suicide events involving 119 female homicide victims in North Carolina, victim separation from the perpetrator was the most prevalent precursor to the deaths (41\%), followed by a history of domestic abuse (29\%; Morton, Runyan, Moracco, \& Butts, 1998). In cases of nonlethal violence against women, studies find patterns of victim/offender relationship similar to those in homicide cases. Specifically, in the National Violence Against Women Survey (NVAWS), the majority of women above the age of 18 who reported victimization experiences said they were physically assaulted (72\%), raped (62\%), or stalked $(60 \%)$ by an intimate partner (Tjaden \& Thoennes, 2000). 
Table I. Known Ages of Homicide Victims by Gender, 2002 and 2003

\begin{tabular}{lcccccc}
\hline Count (row \%) & 0 to 5 & 6 to 17 & 18 to 24 & 25 to 49 & ${\text { Above } 50^{\text {a }}}$ & Total \\
\hline 2002 & & & & & & \\
Male & 331 & 664 & 3,663 & 6,195 & 1,367 & 12,220 \\
& $(2.7 \%)$ & $(5.4 \%)$ & $(30.0 \%)$ & $(50.7 \%)$ & $(11.2 \%)$ & $(100.0 \%)$ \\
Female & 279 & 278 & 588 & 1,854 & 677 & 3,676 \\
& $(7.6 \%)$ & $(7.6 \%)$ & $(16.0 \%)$ & $(50.4 \%)$ & $(18.4 \%)$ & $(100.0 \%)$ \\
2003 & & & & & & \\
Male & 359 & 681 & 3,786 & 6,390 & 1,428 & 12,614 \\
& $(2.8 \%)$ & $(5.4 \%)$ & $(30.0 \%)$ & $(50.4 \%)$ & $(11.3 \%)$ & $(100.0 \%)$ \\
Female & 283 & 207 & 629 & 1,802 & 692 & 3,613 \\
& $(7.8 \%)$ & $(5.8 \%)$ & $(17.4 \%)$ & $(49.9 \%)$ & $(19.2 \%)$ & $(100.0 \%)$ \\
\hline
\end{tabular}

Source: Puzzanchera and Kang (2008). [AQ: 1]

a. Available FBI data do not distinguish an exclusive elderly category ( 65 and older).

Although, across assault type (lethal and nonlethal), the victim-offender relationship appears to consistently point to known or intimate offenders, as the age of the female victim increases, the victim-offender relationship dyad appears to change. Several studies of older victims suggest that violence against elderly women is often committed by strangers (Abrams, Leon, Tardiff, Marzuk, \& Sutherland, 2007; Ahmed \& Menzies, 2002; Kennedy \& Silverman, 1990; Nelson \& Huff-Corzine, 1998). These data suggest that age appears to potentially condition or moderate the victim-offender relationship pattern in cases involving assault or homicide of women.

\section{Lethal Assaults Against Women:Age of the Victim}

Across the life span for females, homicide rates are highest among infants less than 1 year of age (Karch et al., 2008). Among adult women, previous studies of homicide have found that women are overrepresented among the population of elderly victims. Though the FBI's Supplementary Homicide Reports (SHR) do not distinguish elderly Americans (65 years and older) as a separate age category, gender differences in the proportion of victims 50 years and older are still striking in these data. While about half of all homicide victims reflected in FBI data, regardless of gender, are between 25 and 49 years of age, nearly three times as many young men (18 to 24 years of age) as older men (above 50 years of age) are victims of homicide (see Table 1). However, the proportion of older women (aged 50 or older) experiencing homicide is about the same as for young women (18 to 24 years old; Snyder et al., 2007). In other words, while young men experience homicide at rates nearly twice that of young women, this relationship becomes inverse among older Americans. For 2003, for example, the proportion of male homicide victims above the age of 50 was $11.3 \%$, whereas the proportion of female victims above 50 years old was $19.2 \%$ (Table 1 ). 
Giving further evidence of the overrepresentation of women among elderly homicide victims, Abrams et al. (2007) examined 11,850 homicide cases in New York City from 1990 to 1998 and found that women comprised $42.8 \%$ of elderly homicides but only $13.7 \%$ of homicides for victims under the age of 65 . Though the researchers noted that women are demographically overrepresented among the elderly, nevertheless gender-specific homicide rates "suggested that risk factors or vulnerabilities other than demographics alone underlay the increased presences of women" among victims (Abrams et al., 2007, p.1668). In a similar study of 49 elderly homicide cases from 1996 to 2005, 51\% involved a female victim (Koehler, Shakir, Omalu, \& Wecht, 2006). At least two other longitudinal studies from individual medical examiner offices place the proportion of elderly female victims around 40\% (Falzon \& Davis, 1998; Shields, Hunsaker, \& Hunsaker, 2004).

\section{Lethal and Nonlethal Assaults Against Women: Manner of Death and Type of Injury}

The types of injury sustained by victims in lethal and nonlethal assaults have been compared by victim gender and age and by offender type. In nonlethal assaults, studies suggest a link between victim-offender relationship and level of injury (Craven, 1997). In the NVAWS, for example, if the assault was committed by an intimate partner, the victim tended to sustain greater physical injury than if a stranger were the perpetrator (Tjaden \& Thoennes, 2000).

In cases of homicide, for both men and women, firearms are the most common method used to commit the act, but strangulation/suffocation/asphyxiation is nearly seven times more common among female homicide victims (Karch et al., 2008). Drowning and intentional neglect are also more common methods of homicide in women (Karch et al., 2008).

Among elderly homicide victims, Kennedy and Silverman (1990) employed an integrated lifestyle-routine activities approach in an analysis of elderly homicide victims and found that they died more often as a result of a beating at the hands of a stranger offender whose primary motive was burglary or robbery. Koehler and colleagues (2006) recorded specific mechanisms of homicide and injury locations and found that 5 out of 25 female, elder homicides involved combination injury patterns or similar injuries distributed across multiple body areas (Koehler et al., 2006). These injuries would qualify as overkill as defined in that study, translating to roughly $20 \%$ of homicides involving elderly women in the study sample. In general, elderly victims were more likely to experience multiple physical traumas than their younger counterparts. Abrams et al. (2007) found that "beating" was five times more likely to be the cause of death among victims older than 65 than those younger. Likewise, Ahmed and Menzies (2002) found that $35.7 \%$ of elderly victims compared to just $23.7 \%$ of nonelderly victims suffered death by beating or blunt object trauma. These data again suggest that the variables of age and victim-offender relationship moderate rate of homicide and the injury sustained during the violent act, although the specific relationship between those variables is not yet clear. 


\section{Empirical Limitations in Documenting Injury Type Among Female Homicide Victims}

Studies on the homicide of women, and in fact on homicide generally, often use the FBI's annual Uniform Crime Reports (UCR) or other similar data that contain limited information on injury patterns or offender details. Fewer studies comprehensively analyze medical examiner records, investigative and crime scene data contained in police reports, and offender-specific data contained in court or corrections records as acquiring and compiling such data sets is often a prohibitively expensive, lengthy, and labor-intensive process. The recently developed Homicide Injury Scale (HIS) created by Safarik and Jarvis (2005) [AQ: 2], however, did compile the more extensive database and also provided a useful empirical measure of injury severity. The HIS is a homicide-specific supplement to previous techniques of quantifying injury severity among trauma patients, most notably the Injury Severity Score (ISS), which has long been used to assess injury severity across a variety of traumatic situations (Baker, O'Neill, Haddon, \& Long, 1974; Osler, Baker, \& Long, 1997). Specifically, the HIS complements the ISS by allowing the researchers to code traumatic injuries not only as fatal but also to distinguish between a single fatal injury, multiple fatal injuries, and excessive, termed overkill, injuries. In their original study, Safarik and Jarvis examined a comprehensive data set made up of records from 128 elderly homicide cases from 30 states compiled by a special FBI project. The data set for the study was an unusually comprehensive compilation of legal and medical case information. While the HIS provided an important, more sensitive measure of injury severity, no investigation of the fuller descriptive potential of the HIS on a broader of homicide cases has yet been undertaken.

\section{The Present Study}

Although current studies provide data on victim-offender relationship and injury severity in both lethal and nonlethal assault of women, a more detailed analysis of how these variables may relate to one another and change over time is lacking. Specifically, a wealth of data evidences the frequency of intimates among perpetrators of violence against women, but a closer look at the experience of older women reveals a higher percentage of stranger offenders. Although aggregate national data show that intimate partner violence against women tends to be more injurious than stranger violence against women, closer analysis of homicide among older women offers contradictory findings. These differences in the experience of adult women generally and older women specifically and an understanding of how these differences may relate to one another is not yet fully understood. An understanding of homicide patterns among women is also limited by inadequate application of more sensitive measures of injury severity.

The purpose of this study is to address a major gap in the literature on factors that combine to describe assault and homicide of women by analyzing medical examiner records from a sample of 149 female homicide cases. Specifically, study aims are to 
(a) explore how key characteristics of female homicide, specifically including victimoffender relationship and injury severity, vary with age of victims and (b) examine the utility of the HIS across several dimensions not examined in the initial application by Safarik and Jarvis (2005), thereby providing an empirical test of the potential for incorporating the HIS score into a wider range of homicide-related studies and better illuminating the specific associations of certain variables in the assault and homicide of women.

\section{Method}

Through a retrospective review of the database of the records at four Kentucky Medical Examiner Offices, this study identified 149 homicides of female victims occurring during the years 2002-2004. The sample consists of all female homicide victims during these years at least 13 years old at the time of death. Victims younger than 13 , those likely to be victims of child abuse, were excluded from the study along with one case in which the victim's exact age was unknown. The resulting sample of 148 female victims had an age range of 15 to 85 years. The mean age for all victims was 38.85 years (median $=37$ years old). Compared to population estimates of females by race in the state of Kentucky from the 2000 Census (White $=90.2 \%$, African American $=$ $7.4 \%)$, there were significantly fewer Whites $(84.1 \%$ of victims) and significantly more African Americans (13.8\% of victims) represented among female homicide victims. There was only one Hispanic victim; however, this was statistically consistent with the 2000 proportion of Hispanics in the state of Kentucky (1.5\%). There were 13 elderly female victims (above the age of 65 years) comprising $8.8 \%$ of the sample but only $7.4 \%$ of the state population according to the 2000 Census. Two of the 148 female victims of homicide were pregnant at the time of death. For 85 cases (57\%), information about the nature of the relationship between the victim and offender was available in medical examiner records (See Table 2).

Injury data for the present study were extracted by study investigators directly from state medical examiner records. A research team traveled to the four regional medical examiner offices in the state and reviewed final autopsy reports from case records, usually with medical examiners present to answer questions. Most data for this study were taken directly from the final autopsy report that contained information about age, race, toxicology, injuries, a final determination of manner of death (natural, injury, homicide, suicide), and cause of death. To code data for multiple or single cause of death on the HIS, the cause of death and contributing injuries as explicitly stated by the medical examiner was used. This follows from the development of the HIS by Safarik and Jarvis (2005) "to capture the number of causes of death and related injury severity as identified by the medical examiner" (p. 190). Other injuries used to make finer gradations along the HIS scale were taken directly from the final autopsy report's detailed bodily descriptions.

Based on the ISS (Baker et al., 1974) designation of body regions, the injuries described in the autopsy reports were coded according to the following five regions: 
Table 2. Relationship Between Victim and Offender by Age Category

\begin{tabular}{llcc}
\hline Number of victims (\% of total) & & $13-65$ & 65 and older $^{\text {a }}$ \\
\hline Known offender & Intimate partner & $36(26.7 \%)$ & $4(30.8 \%)$ \\
& Ex-intimate partner & $16(11.9 \%)$ & $0(0.0 \%)$ \\
& Family member & $11(8.1 \%)$ & $3(23.1 \%)$ \\
Unknown offender & Acquaintance & $5(3.7 \%)$ & $1(7.7 \%)$ \\
& Stranger & $6(4.4 \%)$ & $2(15.4 \%)$ \\
Total & Missing/unknown & $61(45.2 \%)$ & $3(23.1 \%)$ \\
\hline
\end{tabular}

a. Total percentages add up to more than $100 \%$ due to rounding.

Table 3. The Homicide Injury Scale (HIS)

I Single cause of death only: internal injuries only with no visible related external injuries (e.g., smothering, strangulation, ruptured organs resulting from blunt force trauma)

2 Single cause of death only: internal injuries only with minor related external injuries (e.g., smothering with related abrasions and/or contusions of mouth and face, strangled with related abrasions or ligature marks)

3 Single cause of death only: related external moderate to serious injuries not identified as either excessive or overkill

4 Two or more causes of death: related internal and/or external injuries not identified as either excessive or overkill

5 Single cause of death only: related external injuries identified as either excessive or overkill

6 Two or more causes of death: related internal and/or external injuries in at least one of the causes of death identified as either excessive or overkill

Source: Safarik and Jarvis (2005). [AQ: 3]

(a) head, neck, and face; (b) front torso or chest; (c) abdomen or front lower torso;

(d) back torso; and (e) extremities.

To define injuries as excessive or "overkill," the following definitions were used: If the victims sustained multiple injuries within one or more causes of death (i.e., multiple gunshot wounds) or if multiple wounds of the same type were distributed over two or more body regions and considered causes of death in each (based on Salfati, 2003), then the injuries were considered overkill. Together, the medical examiner's determination of cause(s) of death and related injuries classified by this definition of overkill were used to assign cases a HIS score (see Table 3).

During data collection, every effort was made to record additional data about the crimes from case notes within these files, including the relationship between victim and offender, the victim's marital status, the number of children a victim had, and whether the victim or offender showed a previous record of domestic violence. However, the medical examiner reports were often finished proximal to the homicide but 
before the police case was closed. As a result, only cases where an offender was known when the body was discovered or cases where the medical examiner had testified in a trial had information about relationship status and related details ( 85 cases). In all but one case, the victim's identity was known and therefore the age of the victim at the time of death was recorded from the medical examiner's final autopsy report.

\section{Results}

Consistent with the findings of Safarik and Jarvis (2005), the HIS revealed a statistically significant relationship between severity of injuries and age of the victim. Specifically, the mean for elderly victims was 5.00, whereas women younger than 65 years had a mean score of 4.13 on the HIS $(t=1.987, p=.049)$. If rounded to the nearest interpretable scale value, this distinction reveals that the average elderly female victim displayed injuries indicating excessive brutalization, whereas the average younger victim did not display injuries that met the definition of overkill. With respect to specific patterns of injury, elderly victims were significantly more likely to have suffered multiple stab wounds than younger homicide victims $(t=2.270$, $p=.026$ ). Only $20 \%$ of nonelderly female victims suffered multiple stab wounds, compared to $57.1 \%$ of elderly victims.

Data supplemental to the final autopsy report was only available in $57 \%$ of the cases $(n=85)$. Data supplemental to the coroner/medical examiner file was only available in $57 \%$ of the cases $(n=85)$. However, in $67 \%$ of these cases, the homicide was perpetrated by an intimate or former intimate partner. This translates to at least $38.3 \%$ of all female homicides in Kentucky during the study period being related to intimate partner violence, although exact figures cannot be derived from the present data. According to the FBI's UCR over the same time period, on average $32.5 \%$ of female victims nationwide were killed by intimate partners in cases where the offender had been identified (FBI, 2003, 2004, 2005). The study also found that for elderly victims, there was a significant, moderate, negative correlation with being victimized by an intimate or ex-intimate when the offender was known $(r=-.385$, $p=.000)$. In fact, among cases with known offenders, only $10 \%$ of elderly female victims were killed by an intimate partner, compared to $68.4 \%$ of nonelderly female victims $(t=3.825, p=.000)$.

\section{Discussion}

This small study offers additional illumination on the trends in associations of injury and relationship variables in the homicide of women over their life span. It gives further evidence that these variables change over time as situational contexts of violence against older women appears to differ greatly from the victimization experiences of younger women. Not only has research shown that women make up a higher proportion of elderly victims but also that other characteristics of the attack differ as well. Research in the general population of women has shown that the most common 
offender of homicide against women is a known or intimate offender (Bachman \& Saltzman, 1995; Cooper \& Eaves, 1996; Greenfield et al., 1998); however, data from this study finds that elderly women were much less likely to have been victimized by an intimate partner than their younger counterparts. The present study also appears to support the hypothesis that individuals who victimize elderly women are more likely to use excessive violence than those perpetrating homicides against younger women. This stands in contrast to research on nonlethal assaults of women that show an association between intimacy of the offender and more severe injury (Tjaden \& Thoennes, 2000).

The present research, by incorporating the HIS into a sample of both elderly and nonelderly female victims, demonstrates the utility of the HIS in addressing a key issue with respect to understanding the differential risks faced by elderly women. Bivariate correlation using the HIS reveals a significant relationship between elderly, female victims and the severity of injuries sustained in a fatal attack. This ability to quantify injuries through the HIS contributes significantly to discussions of whether elderly victims experience greater injury as a result of the more serious attacks or simply as a consequence of greater physical frailty than younger victims. Defining overkill as the infliction of multiple wounds to one body area or multiple wounds across many body areas allows researchers to code injury severity based on the brutality of the attacker rather than the extent of damage to the victim. Based on the present study, including this measure of overkill suggests that perpetrators of homicide against elderly victims execute more brutal attacks than those who murder the nonelderly and that the age of the victim is not the only factor in determining injury severity.

By examining the victimization experiences of women in different age groups, researchers can build a more complete understanding of how violence against women changes over the life course. This small study finds that the HIS does indeed have some potential for quantitatively distinguishing between experiences of elderly and nonelderly women in the experience of homicide victimization. The study's generalizability is limited by a relatively small sample size and by its reliance on secondary data analysis from only one type of agency (i.e., medical examiner records). Future research is needed to incorporate this simple measure into broader homicide studies, testing whether age-based differences can be found in injury patterns among men of different age groups or across genders. In addition, larger samples may be able to address questions of injury severity relevant to victim-offender relationship, geographic location, culture, or other demographic variables useful to scholars and policy makers.

The ability to quantify differences in patterns of homicide and homicide-related injuries can be an important means of improving the field's understanding of the circumstances by which women are killed and how those patterns change over time. In addition to growing a scholarly understanding of homicide patterns, information on offender type and the type and severity of injury offenders are likely to inflict can be essential tools for criminal justice professionals who investigate the assault and homicide of women. Advocates and health/mental health care professionals may also be positioned to design intervention programs more uniquely tailored to the experiences 
of women across the age spectrum. Maybe most important of all, these findings are important for prevention experts to inform programs more effectively attending to the unique risks of younger and older women with an eye toward ending violence against women across the age spectrum.

\section{Declaration of Conflicting Interests}

The author(s) declared no potential conflicts of interest with respect to the authorship and/or publication of this article. [AQ: 4]

\section{Financial Disclosure/Funding}

The author(s) received no financial support for the research and/or authorship of this article.

\section{[AQ: 5]}

\section{References}

Abrams, R. C., Leon, A. C., Tardiff, K., Marzuk, P. M., \& Sutherland, K. (2007). "Gray murder": Characteristics of elderly compared with nonelderly homicide victims in New York City. American Journal of Public Health, 97, 1666-1670.

Ahmed, A. G., \& Menzies, R. (2002). Homicide in the Canadian prairies: Elderly and nonelderly killings. Canadian Journal of Psychiatry, 47, 875-880.

Arbuckle, J., Olson, L., Howard, M., Brillman, J., Anctil, C., \& Sklar, D. (1996). Safe at home: Domestic violence and other homicides among women in New Mexico. Annals of Emergency Medicine, 27, 210-215.

Bachman, R., \& Saltzman, L. (1995). Violence against women: Estimates from the redesigned survey (NCJ 154348). Washington, DC: Bureau of Justice Statistics, U.S. Department of Justice.

Baker, S. P., O'Neill, B., Haddon, W., \& Long, W. B. (1974). The injury severity score: A method for describing patients with multiple injuries and evaluating emergency care. Journal of Trauma, 14, 187-196.

Browne, A., \& Williams, K. (1993). Gender, intimacy and lethal violence: Trends from 1967 through 1987. Gender \& Society, 7, 78-98.

Campbell, J. C. (1992) "If I can't have you, no one can": Power and control in homicide of female partners. In J. Radford \& D. E. H. Russell (Eds.), Femicide: The politics of woman killing (pp. 99-113). New York: Twayne.

Campbell, J. D., Webster, D., Koziol-McLain, J., Block, C., Campbell, D., Curry, M. A., et al. (2003). Risk factors for femicide in abusive relationships: Results from a multisite case control study. American Journal of Public Health, 93, 1089-1097.

Cooper, M., \& Eaves, D. (1996). Suicide following homicide in the family. Violence and Victims, 11, 99-112.

Craven, D. (1997). Sex differences in violent victimization, 1994. Bureau of Justice Statistics Special Report (NCJ 164508). Washington, DC: Office of Justice Programs, U.S. Department of Justice.

Ellis, D., \& DeKeseredy, W. S. (1997). Rethinking estrangement, interventions, and intimate femicide. Violence Against Women, 3, 590-609. 
Falzon, A. L., \& Davis, G. G. (1998). A 15-year retrospective review of homicides in the elderly. Journal of Forensic Sciences, 43, 371-374.

Federal Bureau of Investigation. (2003). Crime in the United States: 2004 Uniform Crime Reports. Retrieved June 3, 2008, from http://www.fbi.gov/ucr/cius_04/offenses_reported/ violent_crime/murder.html

Federal Bureau of Investigation. (2004). Crime in the United States: 2004 Uniform Crime Reports. Retrieved June 3, 2008, from http://www.fbi.gov/ucr/cius_04/offenses_reported/ violent_crime/murder.html

Federal Bureau of Investigation. (2005). Crime in the United States: 2004 Uniform Crime Reports. Retrieved June 3, 2008, from http://www.fbi.gov/ucr/cius_04/offenses_reported/ violent_crime/murder.html [AQ: 6]

Fox, J. A., \& Zawitz, M. W. (2007). Homicide trends in the U.S. Retrieved June 3, 2008, from http://www.ojp.usdoj.gov/bjs/pub/pdf/htius.pdf

Greenfield, L. A., Rand, M. R., Craven, D., Flaus, P. A., Perkins, C. A., Ringel, C., et al. (1998). Violence by intimates: Analysis of data on crimes by current or former spouses, boyfriends, and girlfriends (NCJ 167237). Washington, DC: Department of Justice, Bureau of Justice Statistics.

Karch, D. L., Lubell, K. M., Friday, J., Patel, N., \& Williams, D. (2008). Surveillance for violence deaths: National violent death reporting system, 16 states, 2005. Morbidity and Mortality Weekly Report. Retrieved June 3, 2008, from http://www.cdc.gov/mmwr/preview/ mmwrhtml/ss5703a1.htm

Kellermann, A. L., \& Mercy, J. A. (1992). Men, women and murder: Gender-specific differences in rates of fatal violence and victimization. Journal of Trauma, 33, 1-5.

Kennedy, L. W., \& Silverman, R. A. (1990). The elderly victim of homicide: An application of the routine activities approach. Sociological Quarterly, 31, 307-319.

Koehler, S. A., Shakir, A. M., Omalu, B. I., \& Wecht, C. H. (2006). Cause of death among elder homicide victims: A 10-year medical examiner review. Journal of Forensic Nursing, 2, 199-202.

Koss, M. P., Goodman, L. A., Browne, A., Fitzgerald, L. F., Keita, G. P., \& Russo, N. F. (1994). Male violence against women at home, at work, and in the community. Washington, DC: American Psychological Association.

McGuire, K., \& Pastore, A. L. (Eds.). (1996). Sourcebook of criminal justice statistics 1995 (NCJ 176356). Washington, DC: Bureau of Justice Statistics, U.S. Department of Justice.

Mercy, J. A., \& Saltzman, L. E. (1989). Fatal violence among spouses in the United States, 1976-1985. American Journal of Public Health, 79, 595-599.

Moracco, K., Runyan, W., \& Butts, J. D. (1998). Femicide in North Carolina, 1991-1993: A statewide study of patterns and precursors. Homicide Studies, 2, 422-446.

Morton, E., Runyan, W., Moracco, K., \& Butts, J. D. (1998). Partner homicide-suicide involving female homicide victims: A population based study in North Carolina, 1988-1992. Violence and Victims, 13, 91-106.

Nelson, C., \& Huff-Corzine, L. (1998). Strangers in the night: An application of the lifestyleroutine activities approach to elderly homicide victimization. Homicide Studies, 2, 130-159.

Osler, T., Baker, S. P., \& Long, W. (1997). A modification of the Injury Severity Score that both improves accuracy and simplifies scoring. Journal of Trauma-Injury Infection and Critical Care, 43, 922-926. 
Puzzanchera, C., \& Kang, W. (2008). Easy access to the FBI's supplementary homicide reports: 1980-2005. Retrieved http://ojjdp.ncjrs.gov/ojstatbb/ezashr/ [AQ: 7]

Salfati, C. G. (2003). Offender interaction with victims in homicide: A multidimensional analysis of frequencies in crime scene behaviors. Journal of Interpersonal Violence, 18, 490-512.

Sev'er, A. (1997). Recent or imminent separation and intimate violence against women. Violence Against Women, 3, 566-589.

Shields, L. B., Hunsaker, D. M., \& Hunsaker, J. C. (2004). Abuse and neglect: A ten-year review of mortality and morbidity in elders in a large metropolitan area. Journal of Forensic Sciences, 49, 122-127.

Snyder, H., Finnegan, T., \& Kang, W. (2007). Easy access to the FBI's supplementary homicide reports: 1980-2005. Retrieved http://ojjdp.ncjrs.gov/ojstatbb/ezashr/

Stark, E., \& Flitcraft, A. (1996). Preventing gendered homicide. In E. Stark \& A. Flitcraft (Eds.), Women at risk: Domestic violence and women's health (pp. 121-153). Thousand Oaks, CA: Sage.

Tjaden, P., \& Thoennes, N. (2000). Full report of the prevalence, incidence, and consequences of violence against women (NCJ 183781). Washington, DC: National Institute of Justice, Office of Justice Programs, U.S. Department of Justice.

Wilson, M., \& Daly, M. (1993). Spousal homicide risk and estrangement. Violence and Victims, $1,3-16$.

\section{Bios}

Carol E. Jordan is an assistant provost and director of the Center for Research on Violence Against Women and holds faculty appointments in the Department of Psychology and the Department of Psychiatry at the University of Kentucky.

Adam J. Pritchard is a doctoral student in sociology and senior research assistant in the Center for Research on Violence Against Women at the University of Kentucky.

Danielle Duckett is a doctoral student in sociology and research assistant in the Center for Research on Violence Against Women at the University of Kentucky.

Pamela Wilcox is an associate professor in the Division of Criminal Justice at the University of Cincinnati and a faculty associate in the Center for Research on Violence Against Women at the University of Kentucky.

Tracey Corey is the chief medical examiner for the Commonwealth of Kentucky and professor of pathology and associate professor of pediatrics at the University of Louisville School of Medicine.

Mandy Combest is an executive staff advisor in the office of the chief medical examiner of Kentucky. 